\title{
Prognostic value of HMGB1 overexpression in resectable gastric adenocarcinomas
}

\author{
Guoqiang Bao, Qing Qiao, Huadong Zhao and Xianli He*
}

\begin{abstract}
Introduction: $\mathrm{HMGB}$ (High mobility group box 1), originally described as a nuclear protein, is now regarded as a multifunctional protein with a paradoxical dual effect in tumors. In the present study, HMGB1 overexpression and its correlation with the clinicopathologic characteristics and recurrence-free survival were evaluated in gastric adenocarcinomas.
\end{abstract}

Methods: 76 gastric adenocarcinomas surgically removed entered the study. The immunohistochemical staining was used to assess HMGB1 expression through tissue microarray procedure. The clinicopathologic characteristics of all patients were recorded, and the regular follow-up was made for all patients.

Results: Almost all the gastric adenocarcinomas showed HMGB1 positive staining mainly in the nucleus, and the overexpression of HMGB1 was found in cancerous tissues with higher strong reactivity rate, compared with noncancerous tissues (total expression score $\geq 9,42.0 \%$ vs. 9.0\%, $P<0.001$ ). Survival analysis revealed that tumor stage negatively correlated with cancer-free survival $(P=0.022)$. Furthermore, HMGB1 overexpression positively associated with cancer-free survival of resectable gastric adenocarcinomas $(P=0.023)$.

Conclusions: The overexpression of HMGB1 protein indicates that HMGB1 may play a role in the tumorigenesis of gastric adenocarcinomas. And the overexpression of HMGB1 may be a marker of good prognosis of gastric adenocarcinoma given curative resection combined with adjuvant chemotherapy.

\section{Introduction}

Gastric cancer (GC) is the second most common cause of cancer-related death in the world. Many Asian countries, including China, have very high rates of GC. For patients in advanced stages, the five-year survival rate is only about 20 percent. There are many factors that limit the prognosis of the disease. High mobility group box 1 (HMGB1), a nuclear DNA-binding protein, originally described as a nuclear protein that binds to and modifies DNA, stabilizes the structure and function of chromatin and regulates gene transcription. It has been realized that HMGB1 can act either as a DNA binding protein or extracellularly as a cytokine-like danger signal, which is either actively secreted or passively released by necrotic cells[1]. Now HMGB1 is regarded as a central mediator of inflammation by acting as a cytokine, which has been

\footnotetext{
* Correspondence: oldfan@fmmu.edu.cn

1 Department of general surgery, Tangdu Hospital, The Fourth Military Medical University, Xi'an 710038, China

Full list of author information is available at the end of the article
}

reported as a "late" proinflammatory mediator in sepsis $[2,3]$.

HMGB1 plays a role in many clinical conditions such as autoimmunity, acute ischemia-reperfusion injury, cardiovascular disease and cancer [4]. Recent evidences suggest that HMGB1 plays critical roles in the development and progression of numerous tumors [5]. HMGB1 modulates the transcriptional activity in the nucleus, but it is also present in the cytoplasm and outside the cell in certain conditions, associated with the proliferation and metastasis of many tumors, including breast cancer, colon carcinoma, and melanoma[6]. More recently, HMGB1 has been recognized as a proangiogenic factor [7].

In the case of tumors, HMGB1 recognition has a paradoxical dual effect: the reparative inflammatory response promotes tumor neoangiogenesis, cell survival, expansion, and metastases; on the other hand, it triggers protective anti-neoplastic T-cell responses[8,9]. Tumor cell death triggered by chemotherapy or radiotherapy initiates an immunoadjuvant pathway that contributes to the success of cytotoxic treatments. The interaction of 
HMGB1 released from dying tumor cells with Toll-like receptor 4 (TLR4) on dendritic cells (DCs) was required for the cross-presentation of tumor antigens and the promotion of tumor specific cytotoxic T-cell responses $[10,11]$. HMGB1 plays roles in various disease conditions mainly through RAGE (the receptor for advanced glycation end products). HMGB1-RAGE interactions have been found to be important in a number of cancers, which involves the MAPK/ERK pathway[12].

HMGB1 has emerged as a candidate for therapeutic intervention in various disease conditions [13]. However, further basic and clinical studies are warranted to confirm the roles played by HMGB1 in clinical cancer medicine. In the present study, the expression of HMGB1 protein was evaluated with tissue microarray(TMA) and immunohistochemical(IHC) staining procedures to study the prognostic significance of HMGB1 and its correlation with the clinical and histopathologic features of resectable gastric adenocarcinomas.

\section{Patients and methods Patients}

TMAs were prepared for IHC test from a total of 78 consecutive cases of gastric adenocarcinomas operated in our department from December 2007 to October 2008. All the patients was given the radical resection and D1+or D2 lymphadenectomy followed by adjuvant chemotherapy with the regimen ECF (Epirubicin, cisplatin and 5-FU). To all patients, no preoperative therapy was given. The pathologic staging were made according to American Joint Committee on Cancer (AJCC) TNM staging system. The follow-up end point was defined as the recurrence or metastasis of the cancer. The use of the tissue samples in TMA analyses and clinical data was approved by Medical Ethics Committee of The Fourth Military Medical University and the patients. Patients' clinical and histopathologic data were summarized in Table 1.

\section{Tissue Microarrays}

For each case, we selected the tumor foci for the TMA construction during routine diagnosis by marking them on the more representative hematoxylin-eosin (H \& E)stained slide with a waterproof pencil.

The advanced tissue arrayer (ATA-100, Chemicon International, Tamecula, CA, USA) was used to create holes in a recipient paraffin block and to acquire cylindrical core tissue biopsies with a diameter of $1 \mathrm{~mm}$ from the specific areas of the "donor" block. The tissue core biopsies were transferred to the recipient paraffin block at defined array positions. The TMAs contained tissue samples from 78 formalin-fixed paraffin-embedded cancer specimens with known diagnosis, and correlated noncancerous tissues from the same patients.
Table 1: Clinical and histopathologic data of the patients.

\begin{tabular}{lc}
\hline Variables & Number of cases(\%) \\
\hline Number of patients & $78(100 \%)$ \\
Age(y) & \\
$\leq 60$ & $44(56.4 \%)$ \\
$>60$ & $34(43.6 \%)$ \\
Gender & \\
Male & $55(70.5 \%)$ \\
Female & $23(28.5 \%)$ \\
Tumor localisation & \\
Proximal & $33(42.3 \%)$ \\
Distal & $45(57.7 \%)$ \\
Histologic grade & \\
Undifferentiated(G4) & $13(16.7 \%)$ \\
Poorly differentiated(G3) & $27(34.6 \%)$ \\
Moderately differentiated(G2) & $29(37.2 \%)$ \\
Well differentiated(G1) & $9(11.5 \%)$ \\
Tumor stage & \\
Stage I + II & $35(44.9 \%)$ \\
Stage III + IV & $43(55.1 \%)$ \\
Primary tumor & \\
T1-2 & $12(15.4 \%)$ \\
T3-4 & $66(84.6 \%)$ \\
N1-3 & \\
\hline & $34(43.6 \%)$ \\
\hline & $44(56.4 \%)$ \\
\hline
\end{tabular}

The block was incubated in an oven at $45^{\circ} \mathrm{C}$ for $20 \mathrm{~min}$ to allow complete embedding of the grafted tissue cylinders in the paraffin of the recipient block, and then stored at $4^{\circ} \mathrm{C}$ until microtome sectioning.

\section{Immunohistochemical staining}

Rabbit-derived anti-human HMGB1 antibodies were used for IHC detection of HMGB1 protein in TMAs. TMA sections were processed for IHC demonstration of HMGB1 protein by the Biotin-Avidin-Peroxidase detection system (Sigma). The anti-HMGB1 antibodies were used at 1:200 dilutions. Endogenous peroxidase was inhibited by incubation with freshly prepared 3\% hydrogen peroxide with $0.1 \%$ sodium azide. Nonspecific staining was blocked with $0.5 \%$ casein and $5 \%$ normal goat serum. TMAs were incubated with biotinylated goat antirabbit antibodies and ExtrAvidin-conjugated horseradish peroxidase. Staining was developed with diaminobenzidine substrate and sections were counterstained with hematoxylin. Normal mouse serum or PBS replaced antiHMGB1 antibodies in negative controls. 
The quantification evaluation of HMGB1 protein expression HMGB1 expression was semiquantitatively estimated as the total HMGB1 immunostaining score, which was calculated as the sum of a proportion score and an intensity score. The propotion score reflects the fraction of positive staining cells(score $0,<5 \%$; score $1,5 \%-10 \%$; score 2 , 10 - 50\%; score 3, 50 - 75\%; score 4, > 75\%). The intensity score represents the staining intensity(score 0 , no staining signal; score 1 , weak positive signal; score 2 , moderate positive signal; score 3, strong positive signal). Finally, a total expression score was given ranging from 0 to 12 . Based the analysis in advance, the overexpression of HMGB1 was defined as the total expression score $\geq 9$.

\section{Statistical analysis}

Results are expressed as median and range. For statistical analysis, the Chi-square test was made with the software GraphPad Prism, and uni-and multivariate analysis and survival analysis were made with the SPSS 16.0. Significance was defined as $P<0.05$.

\section{Results}

\section{The expression of HMGB1 protein in the gastric} adenocarcinomas

Expression of HMGB1 protein was evaluated by using immunohistochemical staining. As a nonhistone DNAbinding protein, the expression of HMGB1 protein was mainly localized in the nucleus. In gastric adenocarcinoma cells, the expression of HMGB1 protein was also mainly detected in the nucleus (Figure 1B, C). But in rare cases of sample, the positive staining could be found in nucleus and cytoplasm (Figure 1D).

The positive staining was detected in most of gastric adenocarcinoma cells. HMGB1 unexpressed tumors mainly were found in the poorly differentiated adenocarcimas. The difference of HMGB1 expression in peritumoral and normal (distant) tissues was not assessed based on the histopathologic changes and HP status. The positive staining was detected in $69 / 78(88.5 \%)$ adenocarcinoma cells, and 61/78(78.2\%) in non-cancerous cells with no significant difference $(P=0.202$, Table 2$)$. But the rate of HMGB1 overexpression (total expression score $\geq$ 9) was elevated in gastric adenocarcinoma cells, compared with corresponding non-cancerous cells $(41.0 \% v s$. $9.0 \%, P<0.001)$.

\section{The correlation of HMGB1 protein expression with the clinical and histopathologic characteristics}

The relationship between HMGB1 overexpression and various clinical and histopathologic features was analyzed. No significant correlation was found between HMGB1 overexpression with age, or gender (Table 3). As shown in Table 3, the statistically significant difference was found in the groups with district differentiation $(P=$

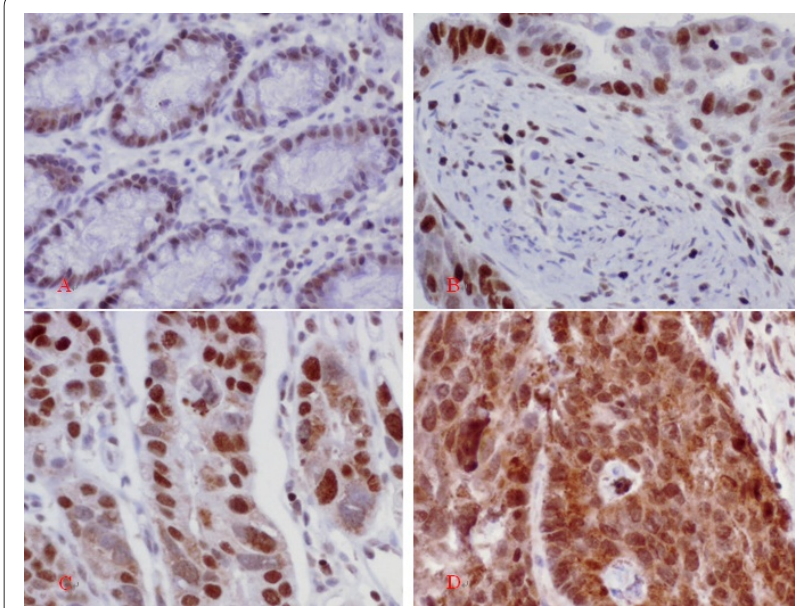

Figure 1 Immunohistochemical detection of HMGB1 protein in different gastric tissues. A: Normal rectal sample. The low-expression of HMGB1 was detected in epithelial and stromal cells B: Gastric adenocarcinoma sample with well differentiation. The immunohistochemical staining showed strong positive signal $(+++)$ in the cancer cells, and low-expression was detected in the stromal cells, which localized in the nucleus. C: Gastric adenocarcinoma sample with poormoderate differentiation. The immunohistochemical staining showed strong positive signal $(+++)$, which mainly localized in the nucleus. D: In rare cases, the strong staining was detected in the nucleus and cytoplasm of the cancer cells. Original magnification $\times 200$

0.012). But, except the significantly elevated rate in $G 1$ group, the difference was no found in G2, G3, and G4 group, compared with the other two groups. The phenomenon perhaps was induced by the distribution bias of the available cases.

According to the pathologic TNM staging, the cases were divided into two groups: stage I + II and stage II + IV. The group with early stage showed elevated rate of HMGB1 over-expression, but no statistically significant difference was found between the two groups (34.3\% vs. $46.5 \%, P=0.356)$. Then, the cases were divided into two groups with lymph node metastasis or no. The rate of HMGB1 overexpression was 21/23(47.7\%) in cancerous specimens with lymph node metastasis, compared with $11 / 23(32.4 \%)$ in cancerous specimens without lymph node metastasis. But no significant difference was found $(P=0.246)$. While, primary tumor infiltrating depth perhaps correlated with HMGB1 overexpression. pT3 + 4 group showed elevated rate of HMGB1 overexpression compared with pT1 +2 group, but no statistical difference was found $(43.9 \%$ vs. $25.0 \%, P=0.340)$ (Table 3 ).

\section{Kaplan-Meier survival analysis}

Regarding the results of cancer-free survival analysis, there was no correlation between gender, age, location, grade of the tumor with prognosis. But the tumor stage and HMGB1 overexpression showed the correlation with cancer-free survival. Survival curves were plotted accord- 
Table 2: Expression of HMGB1 in cancerous tissues and correlated non-cancerous tissues.

\begin{tabular}{|c|c|c|c|c|c|c|c|}
\hline \multirow[t]{2}{*}{ Variables } & \multirow[t]{2}{*}{ All cases(n) } & \multicolumn{2}{|c|}{ Positive expression } & \multirow{2}{*}{$\begin{array}{c}\text { Significance } \\
(P)\end{array}$} & \multicolumn{2}{|c|}{ Overexpression } & \multirow{2}{*}{$\begin{array}{c}\text { Significance } \\
(P)\end{array}$} \\
\hline & & $(n=)$ & $(\%)$ & & $(n=)$ & (\%) & \\
\hline Cancer & 78 & 69 & 88.5 & 0.202 & 32 & 41.0 & $<0.001$ \\
\hline Non-cancer & 78 & 61 & 78.2 & & 7 & 9.0 & \\
\hline
\end{tabular}

ing to the Kaplan-Meier method for the patients with HMGB1 expression status and stage. Tumor stage had a significant effect on cancer-free survival for stage I+II tumors compared with stage III + IV tumors $(P=0.022)$. The expected survival time was $19.0000 \pm 7.35247 \mathrm{~m}$ for Stage I + II tumors $(95 \%$ CI = $16.4743-21.5257), 16.4186$ $\pm 8.69108 \mathrm{~m}$ for stage III $+\mathrm{IV}$ tumors $(95 \% \mathrm{CI}=13.7439$ 19.0933).

Furthermore, survival analysis revealed that HMGB1 overexpression affected cancer-free survival. There was significant difference in cancer-free survival between groups with HMGB1 overexpression and with its lowlevel expression $(P=0.023$, Figure 2$)$. Multivariate analysis showed that the expected cancer-free survival time was $20.4375 \pm 7.28648 \mathrm{~m}$ for tumors with HMGB1 overexpression (95\% CI $=17.8104-23.0646), 15.5870 \pm$ $8.23158 \mathrm{~m}$ for tumors with HMGB1 no-and low-level expression $(95 \% \mathrm{CI}=13.1425$ - 18.0314). HMGB1 overexpression was an independent predictor of cancer-free survival for patients with resectable gastric adenocarcinomas. Furthermore, we analyzed the characteristics of the patients with HMGB1 overexpression who died during the follow-up period. We found the most of the cases had a relatively late disease (Table 4 ).

\section{Discussion}

The occurrence and development of GC correlated with various molecular and genetic incidents. To investigate

Table 3: Expression of HMGB1 in correlation with clinicopathologic variables.

\begin{tabular}{|c|c|c|c|c|c|c|}
\hline \multirow[t]{2}{*}{ Variables } & \multirow[t]{2}{*}{ cases(n) } & \multicolumn{2}{|c|}{ HMGB1 low $<9$} & \multicolumn{2}{|c|}{ HMGB1 high( $\geq 9$ 9) } & \multirow[t]{2}{*}{ Significance $(P)$} \\
\hline & & $(n=)$ & (\%) & $(n=)$ & (\%) & \\
\hline Total & 78 & 46 & 59.0 & 32 & 41.0 & \\
\hline \multicolumn{7}{|l|}{ Gender } \\
\hline Male & 55 & 29 & 52.7 & 26 & 42.3 & 0.129 \\
\hline Female & 23 & 17 & 73.9 & 6 & 26.1 & \\
\hline \multicolumn{7}{|l|}{ Age at surgery } \\
\hline$\leq 60$ & 44 & 29 & 65.9 & 15 & 34.1 & 0.111 \\
\hline$>60$ & 34 & 16 & 47.1 & 18 & 52.9 & \\
\hline \multicolumn{7}{|c|}{ Tumor differentiation } \\
\hline G1 & 9 & 1 & 11.1 & 8 & 88.9 & 0.012 \\
\hline $\mathrm{G} 2$ & 29 & 21 & 72.4 & 8 & 27.6 & \\
\hline G3 & 27 & 17 & 67.0 & 10 & 37.0 & \\
\hline G4 & 13 & 7 & 53.8 & 6 & 46.2 & \\
\hline \multicolumn{7}{|l|}{ Tumor stage } \\
\hline Stage I + II & 35 & 23 & 65.7 & 12 & 34.3 & 0.356 \\
\hline Stage III + IV & 43 & 23 & 53.5 & 20 & 46.5 & \\
\hline \multicolumn{7}{|l|}{ pT stage } \\
\hline pT1-2 & 12 & 9 & 75.0 & 3 & 25.0 & 0.340 \\
\hline pT3-4 & 66 & 37 & 56.1 & 29 & 43.9 & \\
\hline \multicolumn{7}{|l|}{ Nodal status } \\
\hline pNO & 34 & 23 & 67.6 & 11 & 32.4 & 0.246 \\
\hline $\mathrm{pN} 1 \sim 3$ & 44 & 23 & 52.3 & 21 & 47.7 & \\
\hline
\end{tabular}




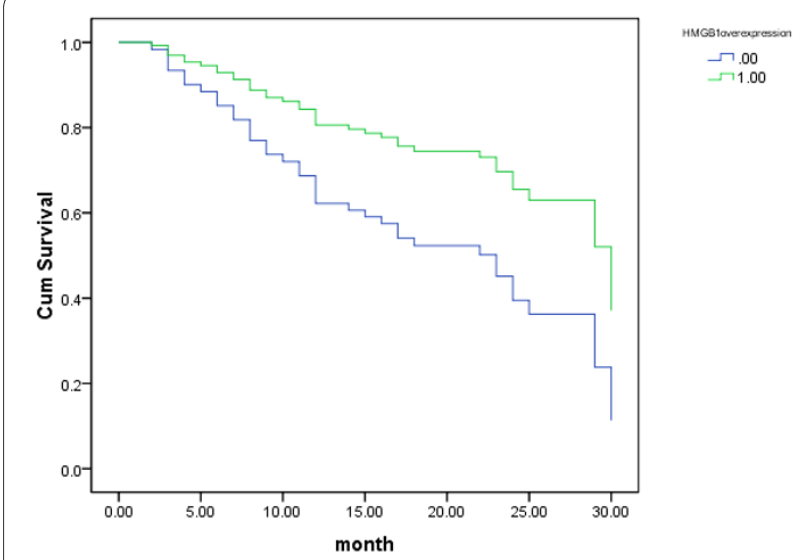

Figure 2 Kaplan-Meier curves of cancer-free survival for HMGB1 overexpression-positive(1) and -negative( 0 ) gastric cancer cases.

the significance of the molecular expression in GC may help us to identify potential treatment target and(or) predictive marker of prognosis and treatment response. Overexpression as well as cytoplasmic localization of HMGB1, particularly in conjunction with its receptor for advanced glycation end products (AGEs), is associated with the proliferation and metastasis of many tumor types [14-16]. Furthermore, HMGB1 secreted from primary tumors decreased the number of macrophages to attenuate the anti-metastatic defense in patients with colorectal cancers, through inducing growth inhibition and apoptosis in macrophages[17,18]. HMGB1 can also influence a variety of important cell types within the tumor microenvironment, including fibroblasts, leukocytes, and vascular cells[19]. So, targeting the HMGB1 ligand or its receptor represents an important potential application in cancer therapeutics [20].
But, HMGB1 may play a controversial role in the occurrence and progression of cancers. Riuzzi $\mathrm{F}$ et al. reported that the HMGB1-RB interaction perhaps induced the HMGB1-mediated transcriptional repression, cell growth inhibition, G1 cell cycle arrest, apoptosis induction, and tumor growth suppression[21]. Furthermore, the functional inactivation of RAGE in myoblasts results in reduced myogenesis, increased proliferation, and tumor formation in vivo [22]. On the other hand, the tumor cell death triggered by chemotherapy or radiotherapy initiates an immunoadjuvant pathway that contributes to the success of cytotoxic treatments. After DNA-alkylating damage, the activation of PARP regulates the translocation of HMGB1 from the nucleus to the cytosol[23]. The interaction of HMGB1 protein released from dying tumor cells with TLR4 on DCs was required for the cross-presentation of tumor antigens and the promotion of tumor specific cytotoxic T-cell responses[10,11,24], which are selectively involved in the cross-priming of anti-tumor $\mathrm{T}$ lymphocytes in vivo $[25,26]$. The controversy indicates that HMGB1 may affect the treatment response of cancers, and HMGB1 may affect the prognosis through complicated pathways.

Of course, the main stream of the study on HMGB1 is that it has the positive correlation with the occurrence, progression, and metastasis of cancers. HMGB1 expressed and secreted by cancer cells are associated with increased metastasis and poorer outcomes in a wide variety of tumors. HMGB1 levels are related with the clinicopathologic characteristics in many cancers. Cheng et al. reported the serum HMGB1 protein levels in hepatocellular carcinoma was significantly higher than those in chronic hepatitis, liver cirrhosis and healthy control, and positive correlation were found between HMGB1 and

Table 4: The clinical and histopathologic characteristics of the patients with HMGB1 overexpression who died during the follow-up period.

\begin{tabular}{|c|c|c|c|c|c|}
\hline No. & Gender & Age & Survival Time(m) & pTNM Stage & Grade \\
\hline 1 & male & 75 & 15 & T4N1M1 & G1 \\
\hline 2 & male & 69 & 23 & T3N1M0 & $\mathrm{G} 2$ \\
\hline 3 & female & 48 & 12 & T3N1M0 & G3 \\
\hline 4 & male & 66 & 12 & T3N3M0 & G3 \\
\hline 5 & male & 65 & 11 & T3N3M0 & G3 \\
\hline 6 & female & 51 & 9 & T4N1M0 & G4 \\
\hline 7 & male & 61 & 10 & T4N1M0 & G4 \\
\hline 8 & female & 58 & 7 & $\mathrm{~T} 3 \mathrm{~N} 2 \mathrm{MO}$ & $\mathrm{G} 2$ \\
\hline 9 & male & 68 & 8 & T3N2M0 & G2 \\
\hline 10 & male & 52 & 11 & T3N2M0 & G4 \\
\hline 11 & male & 69 & 10 & T4N1M0 & G3 \\
\hline 12 & female & 75 & 14 & T4N2M0 & G4 \\
\hline
\end{tabular}


alpha-fetoprotein, and between HMGB1 and the size of tumor. HMGB1 were significant differences among Edmondson grade, TNM stage and Cancer of the Liver Italian Program score[27]. The similar results were also obtained in the study on GC [28].

The study on the correlation of between HMGB1 expression and gastrointestinal cancers can be found recently. Akaike et al. reported the expression of HMGB1 in GC cells with the intestinal type was significantly increased compared to that in the diffuse type, which was positively correlated with the degree of macrophage infiltration inside the tumor microenvironment. And the prognosis of the low HMGB1 group was significantly poorer than that of the high HMGB1 group [29]. Völp et al. reported HMGB1 gene was overrepresented in one third of colon cancers. Correspondingly, HMGB1 protein levels were significantly elevated in $90 \%$ of the 60 colon carcinomas tested compared with corresponding normal tissues evaluable from the same patients [30]. HMGB1 overexpression was significantly associated with tumor invasion, lymph node metastasis, distant metastasis and Duke's stage, and inversely associated with overall survival [31].

In the present study, the expression of HMGB1 was detected in most of the gastric adenocarcinoma samples, as well as the borderline and normal epithelial cells. But the increased expression of HMGB1 protein was found in cancer samples, compared with the borderline and normal (distant) tissues. As we have found, the positive staining signals mainly detected in nucleus of gastric adenocarcinoma cells and stromal cells of cancerous tissues. In rare cases, the strong staining was detected in the nucleus and cytoplasm of the cancer cells. In our another study, there was a higher rate of cytoplasm staining in colorectal cancer cells(data not shown here). The mechanism and the significance need further study.

In the study, the rate of HMGB1 overexpression tended to increase correlated with invasion depth, tumor stage, and lymph node. But no statistical difference was found, which had acceptable difference with the currently reported results. It perhaps indicates that more sensitive and stable methods are needed for the further study. But it was confirmed that gastric adenocarcinoma showed a high rate of HMGB1 overexpression (total expression score $\geq 9$ ). In the group of patients, 32/78(41.0\%) showed the overexpression of HMGB1.

Tumor stage is the current marker of prognosis of GC. In the group of patients, survival analysis showed that tumor stage inversely correlated with cancer-free survival. Furthermore, the survival analysis showed that HMGB1 overexpression positively associated with the cancer-free survival of patients with resectable gastric adenocarcinoma. For GC patients with HMGB1 overexpression, they might have more chance to have a long recurrence-free survival time after curative resection followed adjuvant chemotherapy with ECF regimen.

In conclusion, the high-level expression of HMGB1 protein was detected in gastric adenocarcinoma cells. It consisted with the other researchers' reports. In many gastric adenocarcinomas, the overexpression of HMGB1 was found. The overexpression of HMGB1 was positively correlated with the prognosis of the patients given curative resection and adjuvant chemotherapy.

\section{Competing interests}

The authors declare that they have no competing interests.

\section{Authors' contributions}

GB supervised research project, participated in the data collection, drafted the manuscript. QQ participated in the data collection, supervised ICH. HZ carried out the operation. $\mathrm{XH}$ carried out the operation, acted as corresponding author and did the revisions. All authors read and approved the final manuscript.

\section{Acknowledgements}

This study was supported in part by a grant from National Natural Science Foundation of China (No. 30700810) and Shaanxi Department of Science and Technology(No.2007K12-02(18)). The authors would like to thank Dr Yi Wan(Department of medical statistics, FMMU, China) for his help with statistical work and Dr Haichao Wang(Chief, Basic Science Research Program, Department of Emergency Medicine, NSUH-NYU School of Medicine, Manhasset, NY) for linguistic revision of the manuscript.

\section{Author Details}

Department of general surgery, Tangdu Hospital, The Fourth Military Medical University, Xi'an 710038, China

Received: 21 February 2010 Accepted: 26 June 2010

Published: 26 June 2010

\section{References}

1. Meyer A, Staratschek-Jox A, Springwald A, Wenk H, Wolf J, Wickenhauser C, Bullerdiek J: Non-Hodgkin lymphoma expressing high levels of the danger-signalling protein HMGB1. Leuk Lymphoma 2008, 49:1184-9.

2. Wang H, Bloom O, Zhang M, Vishnubhakat JM, Ombrellino M, Che J, Frazier A, Yang H, Ivanova S, Borovikova L, Manogue KR, Faist E, Abraham E, Andersson J, Andersson U, Molina PE, Abumrad NN, Sama A, Tracey KJ: HMG-1 as a late mediator of endotoxin lethality in mice. Science 1999, 285:248-51

3. Lange SS, Mitchell DL, Vasquez KM: High mobility group protein B1 enhances DNA repair and chromatin modification after DNA damage. Proc Natl Acad Sci USA 2008, 105:10320-5.

4. Mollnes TE: High mobility group box-1 protein - one step closer to the clinic? Crit Care 2008, 12:168.

5. Coffelt SB, Scandurro AB: Tumors sound the alarmin(s). Cancer Res 2008, 68:6482-5.

6. Bartling B, Fuchs C, Silber RE, Simm A: Fibroblasts mediate induction of high mobility group box protein 1 in lung epithelial cancer cells by diffusible factors. Int J Mol Med 2007, 20:217-24.

7. van Beijnum JR, Buurman WA, Griffioen AW: Convergence and amplification of toll-like receptor (TLR) and receptor for advanced glycation end products (RAGE) signaling pathways via high mobility group B1 (HMGB1). Angiogenesis 2008, 11:91-9.

8. Campana L, Bosurgi L, Rovere-Querini P: HMGB1: a two-headed signal regulating tumor progression and immunity. Curr Opin Immuno/ 2008, 20:518-23.

9. Hagemann T, Balkwill F, Lawrence T: Inflammation and cancer: a doubleedged sword. Cancer Cell 2007, 12:300-1.

10. Apetoh L, Tesniere A, Ghiringhelli F, Kroemer G, Zitvogel L: Molecular interactions between dying tumor cells and the innate immune system determine the efficacy of conventional anticancer therapies. Cancer Res 2008, 68:4026-30. 
11. Dong Xda E, Ito N, Lotze MT, Demarco RA, Popovic P, Shand SH, Watkins S, Winikoff S, Brown CK, Bartlett DL, Zeh HJ: High mobility group box I (HMGB1) release from tumor cells after treatment: implications for development of targeted chemoimmunotherapy. J Immunother 2007 , 30:596-606.

12. Rauvala H, Rouhiainen A: RAGE as a receptor of HMGB1 (Amphoterin): roles in health and disease. Curr Mol Med 2007, 7:725-34.

13. Mollnes TE: High mobility group box-1 protein--one step closer to the clinic? Crit Care 2008, 12:168.

14. Ellerman JE, Brown CK, de Vera M, Zeh HJ, Billiar T, Rubartelli A, Lotze MT: Masquerader: high mobility group box-1 and cancer. Clin Cancer Res 2007, 13:2836-48.

15. Allmen EU, Koch M, Fritz G, Legler DF: V domain of RAGE interacts with AGEs on prostate carcinoma cells. Prostate 2008, 68:748-58.

16. Tang D, Kang R, Zeh HJ, Lotze MT: High-mobility group box 1 and cancer. Biochimica et Biophysica Acta 2010, 1799:131-40.

17. Moriwaka Y, Luo Y, Ohmori H, Fujii K, Tatsumoto N, Sasahira T, Kuniyasu H: HMGB1 attenuates anti-metastatic defense of the lymph nodes in colorectal cancer. Pathobiology 2010, 77(1):17-23.

18. Kuniyasu H, Yano S, Sasaki T, Sasahira T, Sone S, Ohmori H: Colon cancer cell-derived high mobility group 1 /amphoterin induces growth inhibition and apoptosis in macrophages. Am J Pathol 2005, 166:751-60

19. Logsdon CD, Fuentes MK, Huang EH, Arumugam T: RAGE and RAGE ligands in cancer. Curr Mol Med 2007, 7:777-89.

20. Lotze MT, DeMarco RA: Dealing with death: HMGB1 as a novel target for cancer therapy. Curr Opin Investig Drugs 2003, 4:1405-9.

21. Jiao Y, Wang HC, Fan SJ: Growth suppression and radiosensitivity increase by HMGB1 in breast cancer. Acta Pharmacol Sin 2007 , 28:1957-67.

22. Riuzzi F, Sorci G, Donato R: RAGE expression in rhabdomyosarcoma cells results in myogenic differentiation and reduced proliferation, migration, invasiveness, and tumor growth. Am J Pathol 2007 171:947-61

23. Ditsworth $D$, Zong $W X$, Thompson CB: Activation of poly(ADP)-ribose polymerase (PARP-1) induces release of the pro-inflammatory mediator HMGB1 from the nucleus. J Biol Chem 2007, 282:17845-54.

24. Apetoh L, Mignot G, Panaretakis T, Kroemer G, Zitvogel L: Immunogenicity of anthracyclines: moving towards more personalized medicine. Trends Mol Med 2008, 14:141-51.

25. Apetoh L, Ghiringhelli F, Tesniere A, Criollo A, Ortiz C, Lidereau R, Mariette C, Chaput N, Mira JP, Delaloge S, André F, Tursz T, Kroemer G, Zitvogel L: The interaction between HMGB1 and TLR4 dictates the outcome of anticancer chemotherapy and radiotherapy. Immunol Rev 2007, 220:47-59.

26. Apetoh L, Ghiringhelli F, Tesniere A, Obeid M, Ortiz C, Criollo A, Mignot G, Maiuri MC, Ullrich E, Saulnier P, Yang H, Amigorena S, Ryffel B, Barrat FJ, Saftig P, Levi F, Lidereau R, Nogues C, Mira JP, Chompret A, Joulin V, ClavelChapelon F, Bourhis J, André F, Delaloge S, Tursz T, Kroemer G, Zitvogel L: Toll-like receptor 4-dependent contribution of the immune system to anticancer chemotherapy and radiotherapy. Nat Med 2007, 13:1050-9.

27. Cheng BQ, Jia CQ, Liu CT, Lu XF, Zhong N, Zhang ZL, Fan W, Li YQ: Serum high mobility group box chromosomal protein 1 is associated with clinicopathologic features in patients with hepatocellular carcinoma. Dig Liver Dis 2008, 40:446-52.

28. Chung HW, Lee SG, Kim H, Hong DJ, Chung JB, Stroncek D, Lim JB: Serum high mobility group box-1(HMGB1) is closely associated with the clinical and pathologic features of gastric cancer. J Trans/ med 2009, 7:38.

29. Akaike H, Kono K, Sugai H, Takahashi A, Mimura K, Kawaguchi Y, Fujii H: Expression of high mobility group box chromosomal protein-1 (HMGB1) in gastric cancer. Anticancer Res 2007, 27:449-57.

30. Völp K, Brezniceanu ML, Bösser S, Brabletz T, Kirchner T, Göttel D, Joos S, Zörnig M: Increased expression of high mobility group box 1 (HMGB1) is associated with an elevated level of the antiapoptotic C-IAP2 protein in human colon carcinomas. Gut 2006, 55:234-42.

31. Yao X, Zhao G, Yang H, Hong X, Bie L, Liu G: Overexpression of highmobility group box 1 correlates with tumor progression and poor prognosis in human colorectal carcinoma. J Cancer Res Clin Oncol 2010, 136:677-84 doi: 10.1186/1477-7819-8-52

Cite this article as: Bao et al., Prognostic value of HMGB1 overexpression in resectable gastric adenocarcinomas World Journal of Surgical Oncology 2010, 8:52

\section{Submit your next manuscript to BioMed Central} and take full advantage of:

- Convenient online submission

- Thorough peer review

- No space constraints or color figure charges

- Immediate publication on acceptance

- Inclusion in PubMed, CAS, Scopus and Google Scholar

- Research which is freely available for redistribution
C BioMed Central 